\title{
The risk and extent of neurologic events are equivalent for high-risk patients treated with transcatheter or surgical aortic valve replacement
}

\author{
Thomas G. Gleason, MD, ${ }^{\mathrm{a}}$ John T. Schindler, MD, ${ }^{\mathrm{a}}$ David H. Adams, MD, ${ }^{\mathrm{b}}$ Michael J. Reardon, MD, \\ Neal S. Kleiman, MD, ${ }^{\mathrm{c}}$ Louis R. Caplan, MD, ${ }^{\mathrm{d}}$ John V. Conte, MD, ${ }^{\mathrm{e}}$ G. Michael Deeb, MD, \\ G. Chad Hughes, Jr, MD, ${ }^{g}$ Sharla Chenoweth, MS, ${ }^{\mathrm{h}}$ and Jeffrey J. Popma, MD ${ }^{\mathrm{d}}$
}

\section{ABSTRACT}

Objectives: This study was designed to characterize the incidence of new clinically detectable neurologic events, or any comparative change in indices of higher cognitive function following transcatheter aortic valve replacement (TAVR) or surgical aortic valve replacement (SAVR) within the framework of a prospective, randomized clinical trial for high-risk patients.

Methods: High-risk patients (predicted SAVR mortality $15 \%$ ) with severe aortic stenosis $(\mathrm{n}=750)$ were randomized $1: 1$ to TAVR or SAVR and underwent evaluation using the National Institutes of Health Stroke Scale (NIHSS) and modified Rankin Scale assessment at each follow-up and any suspected event. Neurologic outcomes were ascertained by a neurologist and further evaluated by Mini-Mental State Examination (MMSE), visual fields testing, gait assessment, hand function, writing evaluation, and drawing assessment.

Results: The 30-day, 1-year, and 2-year stroke rates were 4.9\%, 8.7\%, and $10.9 \%$, respectively, for TAVR and $6.2 \%, 12.5 \%$, and $16.6 \%$, respectively, for SAVR $(P=.46, .11$, and .05 , respectively). All-cause mortality in patients with a major stroke was $83.3 \%$ for TAVR and $54.5 \%$ for SAVR at 2 years $(P=.29)$. Late major stroke was disproportionately higher $(23.8 \%$ at 2 years $)$ among patients with poor iliofemoral access randomized to SAVR. Peripheral vascular disease and falls within 6 months predicted early stroke, and severe aortic calcification and high Charlson score $(\geq 5)$ predicted 1-year stroke post-TAVR. NIHSS and MMSE scores trended higher after SAVR than after TAVR. Lack of dual antiplatelet therapy use during and after TAVR was associated with early stroke.

Conclusions: This study defines an equivalent postprocedural stroke risk, stroke extent, and degree of cognitive change after TAVR or SAVR in a high-risk population, and also defines several predictors of stroke after TAVR. (J Thorac Cardiovasc Surg 2016;152:85-96)

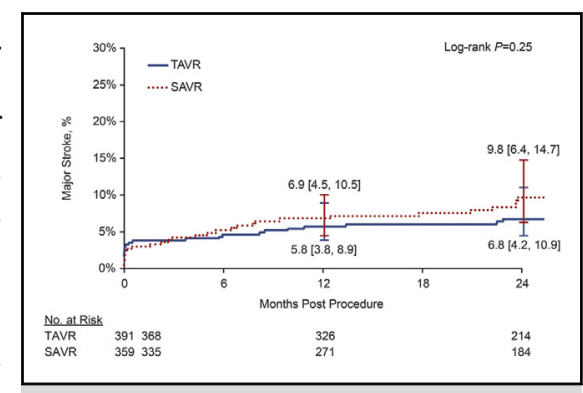

Kaplan-Meier analysis for major stroke after TAVR or SAVR.

\section{Central Message}

This study demonstrates equivalent neurologistadjudicated stroke risk and extent following TAVR or SAVR in a high-risk population.

\section{Perspective}

This study demonstrates equivalent postprocedural, neurologist-adjudicated stroke risk and extent of neurologic injury after TAVR or SAVR in a high-risk population. Several risk factors appear to be predictors of stroke after TAVR, and dual antiplatelet therapy appears to have a protective effect with TAVR. The 2-year mortality rate after TAVR- or SAVRassociated stroke is exceedingly high.

See Editorial Commentary page 97.

See Editorial page 5.
Stroke is a potentially devastating consequence of aortic valve replacement, regardless of method-surgical aortic valve replacement (SAVR) or transcatheter aortic valve replacement (TAVR) - that negatively impacts both health-related quality of life and mortality. ${ }^{1}$ The present investigation sought to clearly define the stroke rate and

\footnotetext{
From the ${ }^{\mathrm{a}}$ University of Pittsburgh School of Medicine, Pittsburgh, Pa; ${ }^{\mathrm{b}}$ Department of Surgery Mount Sinai Medical Center, New York, NY; ' Houston-MethodistDebakey Heart and Vascular Center, Houston, Tex; ${ }^{\mathrm{d}}$ Beth Israel Deaconess Medical Center, Boston, Mass; ' Johns Hopkins University School of Medicine, Baltimore, Md; ${ }^{\mathrm{f}}$ University of Michigan, Ann Arbor, Mich; ${ }^{\mathrm{g}}$ Duke University Medical Center, Durham, NC; and ${ }^{\mathrm{h}}$ Medtronic, Inc, Minneapolis, Minn. This work was funded by Medtronic, Inc.

Read at the 95th Annual Meeting of The American Association for Thoracic Surgery, Seattle, Washington, April 25-29, 2015.
}

Clinicaltrials.gov identifier: NCT01240902.

Received for publication April 23, 2015; revisions received Feb 5, 2016; accepted for publication Feb 16, 2016; available ahead of print April 13, 2016.

Address for reprints: Thomas G. Gleason, MD, Division of Cardiac Surgery, Department of Cardiothoracic Surgery, University of Pittsburgh School of Medicine, 5200 Centre Ave, Suite 715, Pittsburgh, PA 15232 (E-mail: gleasontg@upmc.edu). $0022-5223 / \$ 36.00$

Copyright (c) 2016 by The American Association for Thoracic Surgery http://dx.doi.org/10.1016/j.jtcvs.2016.02.073 


\section{Abbreviations and Acronyms \\ CVA = cerebrovascular accident \\ DAPT $=$ dual antiplatelet therapy \\ NIHSS $=$ National Institutes of Health Stroke Scale \\ MMSE $=$ Mini-Mental State Examination \\ $\mathrm{mRS}=$ modified Rankin Scale \\ SAVR $=$ surgical aortic valve replacement \\ TAVR $=$ transcatheter aortic valve replacement \\ TIA $=$ transient ischemic attack \\ VARC $=$ Valve Academic Research Consortium}

In addition to clinically overt cerebrovascular accidents (CVAs), asymptomatic silent cerebral infarcts have been frequently observed with transcranial Doppler and diffusion-weighted magnetic resonance imaging (MRI). The prevalence of these radiologic findings is found in greater than two-thirds of patients, ${ }^{5-8}$ and there is some evidence to suggest they may be associated with an increased risk of neurocognitive decline. ${ }^{9,10}$

Despite the penetrance of the Society of Thoracic Surgeons Database, there appears to be discrepant postoperative neurologic event rates depending on the neurologic definition used and on the comprehensive nature of the postoperative evaluation. In addition, despite the standardized definition of stroke by the VARC criteria, there appears to be a knowledge gap in the rates of neurologic injuries between patients treated with TAVR and those treated with SAVR. With continued exponential growth in the use of TAVR combined with the potential expansion into lower-risk patient subsets, better understanding of neurologic events is critical.

extent of impairment/deficits of all neurologic events following TAVR or SAVR within the framework of a prospective, randomized clinical trial among patients at high risk for mortality.

Disabling stroke is only one potential neurologic outcome measure that has been well defined. There are other, less obvious neurologic injuries that may or may not have clinical consequences and may be apparent only on detailed neuropsychological testing in the postoperative period. ${ }^{2}$ Brain deficits in cognition, vision, ambulation, and other neurologic-mediated functions are potentially disabling, especially in older individuals. One major finding of previous TAVR trials has been a higher stroke rate in patients undergoing TAVR compared with those undergoing SAVR. Early strokes occurred more frequently in those with a smaller aortic valve area index. ${ }^{3}$ However, other neurologic indices were not prospectively evaluated and neurologist-adjudicated, but rather were evaluated by source document review by a clinical events committee.

Alternatively, the CoreValve US High-Risk Pivotal Trial was designed for prospective, neurologist-adjudicated stroke ascertainment by Valve Academic Research Consortium (VARC)-defined criteria. ${ }^{4}$ Because the 2 most commonly used scores, the National Institutes of Health Stroke Scale (NIHSS) and modified Rankin Scale (mRS), do not adequately assess some important brain functions, the neurologic substudy within the High-Risk Pivotal Trial, reported here for the first time, aimed to more comprehensively evaluate the neurologic effects and/or complications of TAVR and SAVR in high-risk patients.

\section{METHODS \\ CoreValve US High-Risk Pivotal Randomized Cohort}

The CoreValve US High-Risk Pivotal Trial was a prospective, multicenter, randomized, controlled study performed at 45 clinical sites in the United States. Each site's Institutional Review Board approved the study protocol (ClinicalTrials.gov no. NCT01240902), and all patients provided written informed consent. Patients with severe symptomatic aortic stenosis and an increased risk of mortality (as determined by 2 cardiac surgeons and 1 interventional cardiologist at the investigative site estimated that the risk of death within 30 days after surgery was $\geq 15 \%$, and the risk of death or irreversible complications within 30 days after surgery was $<50 \%)^{11}$ were randomized to TAVR or SAVR. According to trial protocol, the TAVR patients were strongly recommended to take aspirin (81-325 mg) and an additional antiplatelet agent (most commonly clopidogrel $75 \mathrm{mg}$ ) starting 3 days before the procedure unless medically contraindicated and for at least 3 months after implantation. All TAVR patients not receiving anticoagulant therapy (eg, warfarin or a novel oral anticoagulant) also received a clopidogrel load (300 $\mathrm{mg}$ ) on the day of the procedure. There were no specified recommendations for aspirin or antiplatelet use in the SAVR patients, although these data were recorded. Any abnormality in the neurologic evaluation triggered a neurology consultation and imaging. Transient ischemic attack and stroke were defined in accordance with VARC-1 criteria. ${ }^{12}$

Modified Rankin Scale ( $\mathrm{mRS}$ ) assessments were required for all suspected neurologic events. The mRS scores range from 0 to 6 , correlating with perfect health without symptoms to death. ${ }^{13}$ To ensure uniformity of evaluation, directions for evaluation and items to consider in separating mRS scores of 2 to 4 were distributed to all neurologic investigators. The NIHSS assessment was performed at all scheduled follow-up visits in all patients.

\section{Neurologic Substudy}

Patients enrolled in the High-Risk Pivotal Trial were eligible to also participate in a neurologic substudy (Figure 1). The inclusion and exclusion criteria for the substudy were the same except for the added exclusion of roll-in patients. The purpose of the substudy was to further evaluate the 


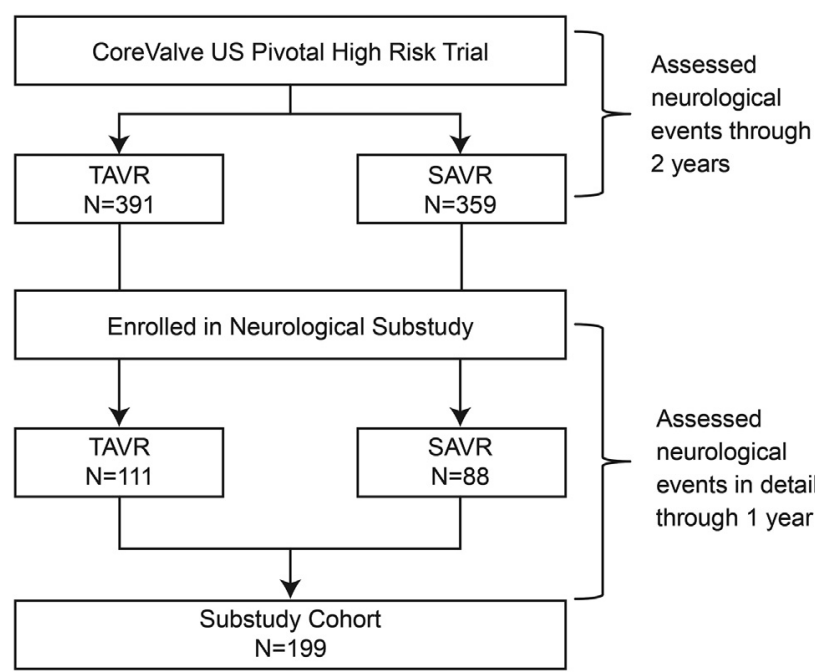

FIGURE 1. Patient disposition. TAVR, Transcatheter aortic valve replacement; $S A V R$, surgical aortic valve replacement.

neurologic effects of the CoreValve System in the treatment of symptomatic severe aortic stenosis in patients necessitating aortic valve repair, and all patients were evaluated by the NIHSS and mRS and subjected to a battery of tests.

The Mini-Mental State Examination (MMSE) was used to quantify cognitive abilities. ${ }^{14,15}$ Writing ability was analyzed along with tests of drawing and copying ability, and visual field, gait, and hand strength and functional assessments were performed.

Endpoints. The primary endpoint for the neurologic substudy was the rate of Clinical Events Committee-adjudicated strokes (of any severity) and transient ischemic attacks (TIAs) at 1 year. Secondary endpoints included periprocedural neurologic injury (stroke, TIA, and encephalopathy), which was evaluated at discharge or at 7 days postprocedure, whichever occurred first. Additional endpoints included quantification and qualification of neurologic deficits seen after TAVR or SAVR. Encephalopathy was defined as episodes of confusion, agitation, and/or combativeness; alterations and fluctuations in levels of consciousness; and acute problems with cognition, including memory and changes in perception, including hallucinations. ${ }^{16}$

Patient assessment. Stroke events were defined based on the original VARC-1 definitions. ${ }^{4}$ In addition to the procedures required for the CoreValve Trial, ${ }^{17}$ the neurologic substudy patients were clinically evaluated by a neurologist at baseline, at discharge or 7 days after the index procedure (whichever occurred first), and at 1 year postprocedure. Patients were also assessed at baseline, discharge, and 1 year postprocedure using the following measures: NIHSS, MMSE, ${ }^{14,18}$ visual fields testing, gait assessment, hand function assessment, and writing and drawing evaluation. For the purpose of our study, a neurologic deficit was defined as an increase in NIHSS score of $\geq 2$ or a decrease in the MMSE score by $>4$.

Visual field testing was performed individually and bilaterally in each of the 4 visual quadrants using finger counting or a visual threat. Any abnormalities in target detection warranted more precise testing. Gait assessment included asking the patient to walk down the corridor (if ambulatory) under observation while noting any visually apparent abnormalities of gait (eg, ataxia, lateralized hemiparesis, shuffling steps). Muscle power is typically graded on a scale of 0 to $5^{19}$; however, we used a scale of 0 to 10 , to enable documentation of subtleties in potential deficits. ${ }^{20}$ On the 0 to 10 scale, 0 represents no muscle contraction and 10 represents normal strength. A deficit was noted when a normal assessment at baseline found a decrease of $\geq 2$.
A writing evaluation was performed by asking the patient to write 2 sentences about a given subject. A deficit was noted if the patient passed at baseline and failed at follow-up assessment. For the drawing assessment, the patient was asked to draw a clock face, put the numbers in the correct positions, and draw the hands to indicate a particular time. The assessment was scored on a scale of 0 to 4 , with 1 point for drawing a closed circle, 1 for including the correct 12 numbers, 1 for placing the numbers in the correct positions, and 1 for placing the hands in the correct positions. A deficit was noted to have occurred if a patient who passed at baseline failed (missed at least $1 \mathrm{item}$ ) at follow-up assessment. The Clinical Events Committee that participated in the overall CoreValve Trial adjudicated the neurologic events for the substudy.

Statistical analyses. Continuous variables are presented as mean \pm standard deviation and were compared using the Student $t$ test. Categorical data were compared using the $\chi^{2}$ or Fisher exact test. Kaplan-Meier analysis using the log-rank test was used to compare time to events. A Cox proportional hazards model was used for the univariable and multivariable analyses. Multivariable predictors of stroke were identified from univariable predictors with a $P$ value $<.05$. Stepwise multivariable analyses were performed. The significance level thresholds for entry and exit of independent variables were set at 0.10 . All statistical analyses were performed with SAS version 9.2 (SAS Institute, Cary, NC).

\section{RESULTS \\ High-Risk Pivotal Trial}

Baseline characteristic and primary clinical outcomes of the CoreValve Trial through 2 years have been reported previously. ${ }^{17,21}$ The rates of neurologic events at 30 days, 1 year, and 2 years are shown in Table 1 . Overall, the rate of stroke events was higher in the patients treated with SAVR compared with those treated with TAVR $(16.6 \%$ vs $10.9 \% ; P=.05)$. Kaplan-Meier estimates of stroke or TIA and major stroke through 2 years are shown in Figure 2. The distribution of strokes occurring within the first 30 days are clustered in the first few days, but become more evenly distributed beyond 30 days out to 2 years (Figure 3).

Starting at the time stroke was observed (day 0), mortality in patients with any stroke was twice as high in the TAVR group compared with the SAVR group (Figure 4, A). Among patients who sustained a major stroke during the first 30 days postprocedure, mortality was high through 2 years in both groups, $83.3 \%$ for TAVR and $54.5 \%$ for SAVR (log-rank $P=.29$ ) (Figure $4, B$ ).

Predictors of neurologic events. We evaluated predictors of neurologic events that occurred early, between day 0 and day 30 postprocedure, and at 1 year postprocedure. Predictors of neurologic events for the patients treated with TAVR and SAVR are presented in Table 2.

Effect of access route on neurologic events. Of the 750 patients in the as-treated cohort, 124 patients were deemed to have unsuitable anatomy for TAVR implantation via the iliofemoral access route. There were significantly more neurologic events in patients without iliofemoral access in the SAVR group compared with the TAVR group (Table 3). Anticoagulation and/or antiplatelet use. A significantly higher percentage of TAVR patients than SAVR patients 
TABLE 1. Clinical outcomes to 2 years for the as-treated cohort from the High-Risk Pivotal Trial

\begin{tabular}{|c|c|c|c|c|c|c|c|c|c|}
\hline \multirow[b]{3}{*}{ Outcome } & \multicolumn{9}{|c|}{ Kaplan-Meier rate (no. of patients) } \\
\hline & \multicolumn{3}{|c|}{$30 \mathrm{~d}$} & \multicolumn{3}{|c|}{$1 \mathbf{y}$} & \multicolumn{3}{|c|}{$2 y$} \\
\hline & TAVR & SAVR & $\boldsymbol{P}$ & TAVR & SAVR & $\boldsymbol{P}$ & TAVR & SAVR & $\boldsymbol{P}$ \\
\hline Any stroke or TIA & $5.7(22)$ & $6.5(23)$ & .67 & $10.3(39)$ & $14.1(47)$ & .14 & $13.2(48)$ & $17.8(56)$ & .13 \\
\hline Stroke & $4.9(19)$ & $6.2(22)$ & .46 & $8.7(33)$ & $12.5(42)$ & .11 & $10.9(40)$ & $16.6(52)$ & .05 \\
\hline Major stroke & $3.9(15)$ & $3.1(11)$ & .55 & $5.8(22)$ & $6.9(23)$ & .61 & $6.8(25)$ & $9.8(30)$ & .25 \\
\hline Ischemic & $3.6(14)$ & $2.5(9)$ & .39 & $5.0(19)$ & $5.4(18)$ & .87 & $5.7(21)$ & $6.7(21)$ & .70 \\
\hline Hemorrhagic & $0.3(1)$ & $0.0(0)$ & .34 & $0.8(3)$ & $0.9(3)$ & .88 & $1.2(4)$ & $1.8(5)$ & .58 \\
\hline Undetermined & $0.0(0)$ & $0.6(2)$ & .14 & $0.0(0)$ & $0.6(2)$ & .14 & $0.3(1)$ & $1.4(4)$ & .13 \\
\hline Minor stroke & $1.0(4)$ & $3.4(12)$ & .03 & $3.0(11)$ & $6.0(20)$ & .047 & $4.2(15)$ & $7.3(23)$ & .08 \\
\hline Ischemic & $0.8(3)$ & $3.1(11)$ & .02 & $2.7(10)$ & $5.4(18)$ & .06 & $4.0(14)$ & $5.8(19)$ & .20 \\
\hline Hemorrhagic & $0.0(0)$ & $0.3(1)$ & .30 & $0.0(0)$ & $0.6(2)$ & .13 & $0.0(0)$ & $1.5(4)$ & .03 \\
\hline Undetermined & $0.3(1)$ & $0.0(0)$ & .34 & $0.3(1)$ & $0.0(0)$ & .34 & $0.3(1)$ & $0.0(0)$ & .34 \\
\hline TIA & $0.8(3)$ & $0.3(1)$ & .36 & $1.6(6)$ & $1.6(5)$ & .92 & $2.6(9)$ & $1.6(5)$ & .41 \\
\hline $\mathrm{ICH}$ & $0.0(0)$ & $0.0(0)$ & - & $0.8(3)$ & $0.7(2)$ & .78 & $1.2(4)$ & $0.7(2)$ & .52 \\
\hline Encephalopathy* & $9.6(37)$ & $17.1(61)$ & .003 & $13.2(50)$ & $19.6(69)$ & .01 & $13.9(52)$ & $20.6(72)$ & .01 \\
\hline
\end{tabular}

$T A V R$, Transcatheter aortic valve replacement; SAVR, surgical aortic valve replacement; TIA, transient ischemic attack; ICH, intracranial hemorrhage. *Patients with nonfocal global encephalopathy were not reported as a stroke without unequivocal evidence based on neuroimaging studies.

were treated with an antiplatelet agent in addition to aspirin, and this differences also held for TAVR and SAVR patients who experienced a stroke up to the 2-year mark (Tables 4 and 5). Differences between the groups in the use of warfarin or another novel oral anticoagulant along with
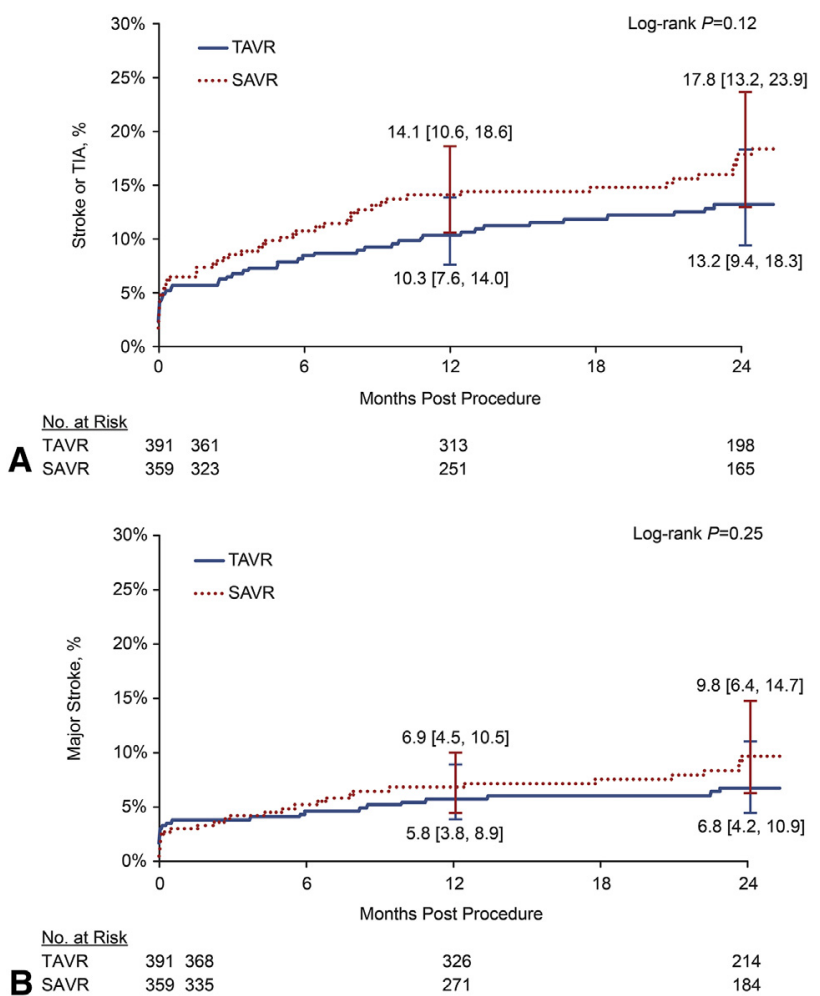

FIGURE 2. Kaplan-Meier analysis for (A) stroke or TIA and (B) major stroke in the TAVR and SAVR arms of the High-Risk Pivotal Trial through 2 years. TAVR, Transcatheter aortic valve replacement; SAVR, surgical aortic valve replacement; TIA, transient ischemic attack. aspirin were not as marked, although all 3 drug classes (aspirin, clopidogrel, and warfarin or novel oral anticoagulant) were used in a greater percentage of TAVR patients compared with SAVR patients, including those who experienced a stroke. Among TAVR patients, nonuse of dual antiplatelet therapy (DAPT) was associated with experiencing a stroke within 3 months of the procedure; however, this association was not true among SAVR patients (Table 6). Interestingly, among patients who had a stroke within 1 year of the procedure, SAVR patients were less likely than TAVR patients to have received DAPT at discharge; a similar trend was seen at the 3-month mark (Table 7).

\section{Neurologic Substudy}

The substudy cohort included 199 high-risk patients (111 undergoing TAVR and 88 undergoing SAVR). Baseline demographic data, clinical characteristics, and data on frailty, disabilities, and comorbidities are provided in Table 8 . The rate of any stroke and TIA at 1 year was $11.2 \%$ for the TAVR group and $13.2 \%$ for the SAVR group. The rate of major stroke at 1 year was $2.7 \%$ for the TAVR group and $6.1 \%$ for the SAVR group.

NIHSS. Eleven patients ( 3 in the TAVR group [3.5\%] and 8 in the SAVR group [12.7\%]) exhibited signs of cognitive impairment (NIHSS score increase $\geq 2$ ) at discharge compared with baseline. Of these, all 3 TAVR patients and 3 of the 8 SAVR patients had a neurologic event. At 1 year, 1 TAVR patient $(1.5 \%)$ and 2 SAVR patients $(4.9 \%)$ had a NIHSS score increase of $\geq 2$ compared with baseline, and all 3 of these patients had a neurologic event reported before assessment (Table 9).

MMSE. Of the 134 patients (79 in the TAVR group and 55 in the SAVR group) with documented MMSE scores at 

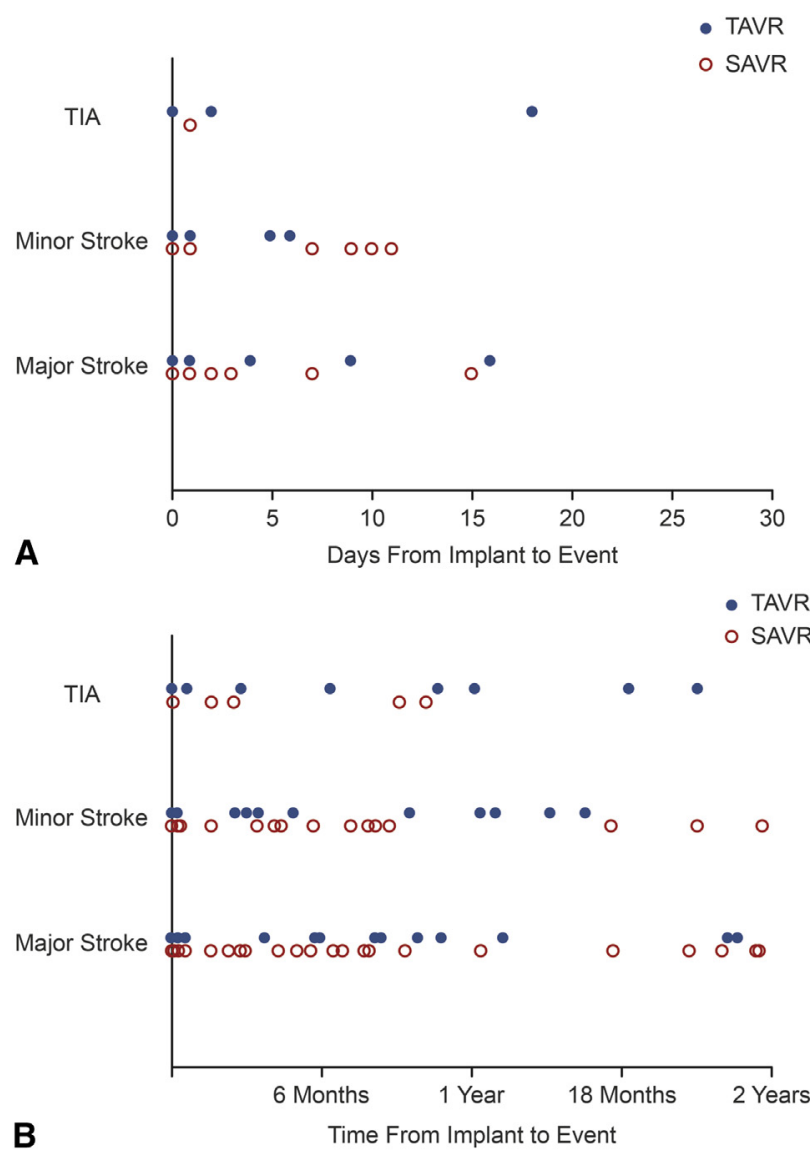

FIGURE 3. Distribution of the occurrences of TIAs and major and minor strokes through (A) 30 days and (B) 2 years. TAVR, Transcatheter aortic valve replacement; SAVR, surgical aortic valve replacement; TIA, transient ischemic attack.

discharge, 2 TAVR patients (2.5\%), and 6 SAVR patients $(10.9 \%)$ had a decrease of $>4$ points over baseline. Both of the TAVR patients and 2 of the 6 SAVR patients had a documented neurologic event before assessment. At 1 year, among the 102 patients (62 in the TAVR group and 40 in the SAVR group) with recorded MMSE scores, 5 TAVR patients $(8.1 \%)$ and 1 SAVR patient $(2.5 \%)$ had a decrease of $>4$ points. One of the TAVR patients and the SAVR patient had a documented neurologic event before assessment.

Visual field testing. Of the 172 patients ( 95 in the TAVR group and 77 in the SAVR group) without any field defect at baseline, 1 TAVR patient and 1 SAVR patient had a reported defect at discharge. The TAVR patient had encephalopathy, whereas the SAVR patient had no neurologic event reported. At 1 year, 2 SAVR patients had a visual field defect, 1 with a minor stroke and the other with no neurologic event reported.

Gait assessment. Of the 135 patients with recorded gait assessment data (77 in the TAVR group and 58 in the SAVR group), abnormal findings were found in 6 TAVR

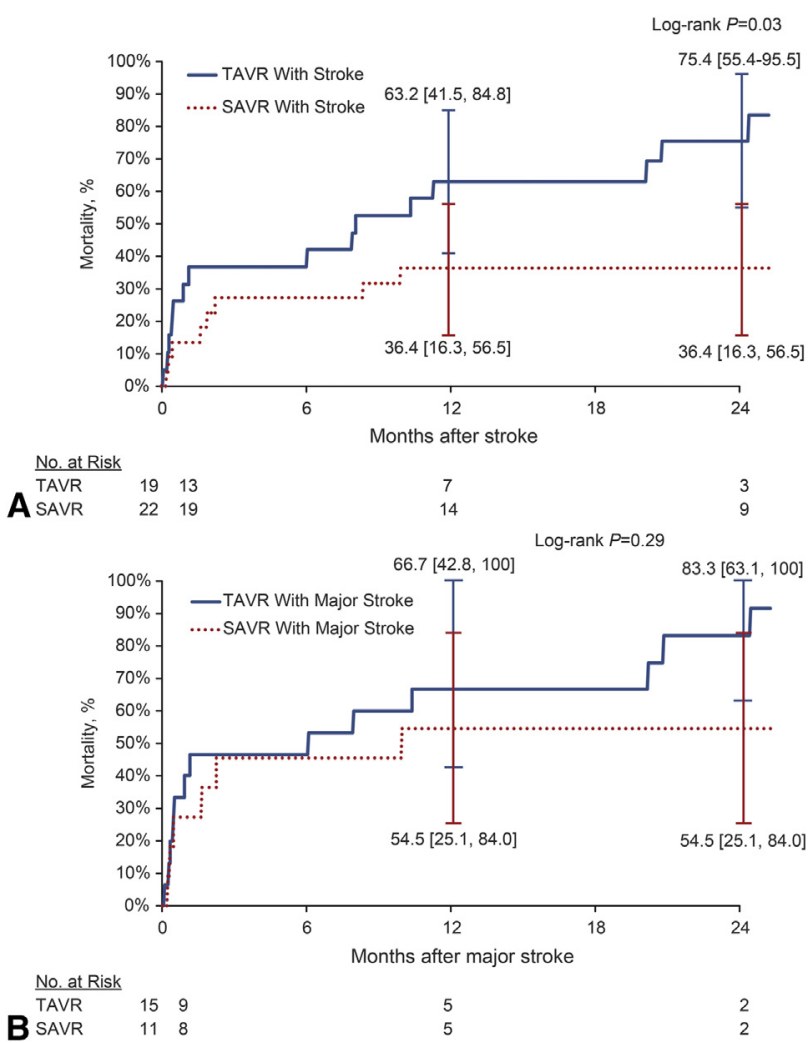

FIGURE 4. Kaplan-Meier estimates of mortality for (A) patients with any stroke and (B) patients with major stroke within 30 days for the TAVR and SAVR arms of the High- Risk Pivotal Trial through 2 years. This time-to-event analysis assigned the day on which the stroke event occurred as day 0. TAVR, Transcatheter aortic valve replacement; SAVR, surgical aortic valve replacement.

patients $(7.8 \%)$ and 9 SAVR patients $(15.5 \%)$. One TAVR patient had associated encephalopathy, and 2 SAVR patients had a neurologic event reported before assessment (1 with minor stroke and 1 with encephalopathy). At 1 year, $6.8 \%$ of the TAVR patients and $7.7 \%$ of the SAVR patients had abnormal gait assessment findings. Only 1 TAVR patient had a neurologic event (minor stroke) reported before assessment.

Motor assessment. Of the 97 patients with normal left motor assessment findings at baseline, the rate of weakness at discharge was $7.2 \%$ in the TAVR group and $6.5 \%$ in the SAVR group. None of the affected patients had a neurologic event before assessment. At 1 year, no TAVR patients and 2 of 35 SAVR patients $(5.7 \%)$ had with notable weakness; 1 of these patients had a neurologic event. In patients with normal right motor assessment findings at baseline, the prevalence of weakness at discharge was $7.2 \%$ in the TAVR group and $10.4 \%$ in the SAVR group. A neurologic event was documented before assessment in 2 of the TAVR patients and none of the SAVR patients. At 1 year, none of the TAVR patients and 2 of 37 SAVR patients had 
TABLE 2. Predictors of early and late stroke after aortic valve replacement

\begin{tabular}{|c|c|c|c|c|c|c|c|}
\hline \multirow[b]{2}{*}{ Predictor } & \multirow[b]{2}{*}{ Kaplan-Meier rate, $\%[95 \%$ CI $], n$} & \multicolumn{3}{|c|}{ Univariable analysis } & \multicolumn{3}{|c|}{ Multivariable analysis } \\
\hline & & HR & $95 \%$ CI & $P$ value & HR & $95 \%$ CI & $P$ value \\
\hline \multicolumn{8}{|c|}{ Predictors of early (0-30 d) stroke after TAVR } \\
\hline Peripheral vascular disease & 8.3 [4.9-13.9], 159 & 3.21 & $1.22-8.44$ & .02 & 3.16 & $1.18-8.44$ & .02 \\
\hline Nocturnal bipap & $13.8[5.4-32.7], 29$ & 3.32 & $1.10-10.0$ & .03 & & & \\
\hline Falls in past $6 \mathrm{mo}$ & 9.9 [4.8-19.6], 72 & 2.91 & $1.13-7.51$ & .03 & 3.18 & $1.23-8.21$ & .02 \\
\hline \multicolumn{8}{|l|}{ Predictors of 1-y stroke after TAVR } \\
\hline Peripheral vascular disease & 12.4 [8.1-18.7], 159 & 2.06 & $1.03-4.10$ & .04 & & & \\
\hline Severe aortic calcification & $17.7[9.2-32.3], 47$ & 2.42 & $1.09-5.36$ & .03 & 2.37 & $1.07-5.26$ & .03 \\
\hline History of hypertension & $7.8[5.4-11.1], 372$ & 0.28 & $0.11-0.73$ & .009 & 0.26 & $0.10-0.68$ & .006 \\
\hline Charlson Comorbidity Score $\geq 5$ & $13.3[9.3-18.9], 211$ & 3.95 & $1.63-9.57$ & .002 & 3.91 & $1.61-9.48$ & .003 \\
\hline \multicolumn{8}{|l|}{ Predictors of 1-y stroke after SAVR } \\
\hline NYHA class III/IV & $11.1[7.9-15.3], 312$ & 0.47 & $0.23-0.96$ & .04 & & & \\
\hline Angina & $6.0[2.5-13.9], 91$ & 0.38 & $0.15-0.97$ & .04 & 0.38 & $0.15-0.97$ & .04 \\
\hline
\end{tabular}

No univariable or multivariable predictors of early stroke were found for the SAVR group. An $\alpha$ value of 0.05 was used to select univariable predictors, and a value of 0.10 was used for multivariable predictors. $C I$, Confidence interval; $H R$, hazard ratio; TAVR, transcatheter aortic valve replacement; SAVR, surgical aortic valve replacement; $N Y H A$, New York Heart Association.

documented weakness; both of these patients had a neurologic event.

Writing evaluation. Of the 79 patients who underwent a writing evaluation, the failure rate was $5.1 \%$ in the TAVR group and $8.5 \%$ in the SAVR group, although all patients had passed at baseline. Only 1 patient in each group had a neurologic event. At 1 year, $1.6 \%$ of the TAVR group and $10 \%$ of the SAVR group failed the test; of these, 1 SAVR patient had an event.

Drawing assessment. Of the 90 patients who underwent a drawing assessment, $23.5 \%$ of the TAVR patients and $25.6 \%$ of the SAVR patients failed at least 1 portion of the assessment, although all patients had passed all portions at baseline. There were 2 patients with a neurologic event in each group. At 1 year, $10.9 \%$ of the TAVR patients and $11.1 \%$ of the SAVR patients failed the test. A neurologic event was noted in 2 of the SAVR patients.

\section{DISCUSSION}

The first reported results of the "inoperable" risk cohort (cohort B) from the seminal Placement of Aortic Transcatheter Valves (PARTNER) Trial served as a bellwether for stroke risk associated with TAVR, revealing a higher stroke rate at 30 days in the TAVR arm compared with medical therapy $(6.7 \%$ vs $1.7 \% ; P=.04){ }^{22}$ This report was followed by an evaluation of the high-risk cohort (PARTNER cohort A), which showed a 2-fold higher stroke rate in the TAVR arm compared with the SAVR arm $(4.6 \%$

TABLE 3. Neurologic events in the High-Risk Pivotal Trial by access route and treatment cohort

\begin{tabular}{|c|c|c|c|c|c|c|c|c|c|c|c|c|}
\hline \multirow[b]{3}{*}{ Event } & \multicolumn{4}{|c|}{$30 \mathrm{~d}$} & \multicolumn{4}{|c|}{$1 \mathbf{y}$} & \multicolumn{4}{|c|}{$2 y$} \\
\hline & \multicolumn{2}{|c|}{ Iliofemoral } & \multicolumn{2}{|c|}{ Non-iliofemoral } & \multicolumn{2}{|c|}{ Iliofemoral } & \multicolumn{2}{|c|}{ Non-iliofemoral } & \multicolumn{2}{|c|}{ Iliofemoral } & \multicolumn{2}{|c|}{ Non-iliofemoral } \\
\hline & TAVR & SAVR & TAVR & SAVR & TAVR & SAVR & TAVR & SAVR & TAVR & SAVR & TAVR & SAVR \\
\hline Any stroke or TIA & $5.9(19)$ & $5.3(16)$ & $4.5(3)$ & $12.3(7)$ & $10.8(34)$ & $12.5(35)$ & $7.7(5)^{*}$ & $22.3(12)^{*}$ & $14.2(42)$ & $15.6(41)$ & $7.7(5) \dagger$ & $30.0(15) \dagger$ \\
\hline Stroke & $5.0(16)$ & $5.0(15)$ & $4.5(3)$ & $12.3(7)$ & $8.9(28)$ & $10.7(30)$ & $7.7(5)^{*}$ & $22.3(12)^{*}$ & $11.5(35)$ & $14.1(37)$ & $7.7(5) \dagger$ & $30.0(15) \dagger$ \\
\hline Major stroke & 3.7 (12) & $2.0(6)$ & $4.5(3)$ & $8.8(5)$ & 5.7 (18) & $4.6(13)$ & $6.1(4)^{*}$ & $18.7(10)^{*}$ & $6.9(21)$ & $7.1(18)$ & $6.1(4)^{*}$ & $23.8(12)^{*}$ \\
\hline Ischemic & $3.4(11)$ & $1.7(5)$ & $4.5(3)$ & $7.0(4)$ & 4.8 (15) & $3.6(10)$ & $6.1(4)$ & $15.4(8)$ & $5.5(17)$ & $4.6(12)$ & $6.1(4)$ & $17.8(9)$ \\
\hline Hemorrhagic & $0.3(1)$ & $0.0(0)$ & $0.0(0)$ & $0.0(0)$ & $1.0(3)$ & $0.7(2)$ & $0.0(0)$ & $1.9(1)$ & $1.4(4)$ & $1.3(3)$ & $0.0(0)$ & $5.0(2)$ \\
\hline Undetermined & $0.0(0)$ & $0.3(1)$ & $0.0(0)$ & $1.8(1)$ & $0.0(0)$ & $0.3(1)$ & $0.0(0)$ & $1.8(1)$ & $0.4(1)$ & $1.3(3)$ & $0.0(0)$ & $1.8(1)$ \\
\hline Minor stroke & $1.3(4)$ & $3.0(9)$ & $0.0(0)$ & $5.3(3)$ & $3.2(10)$ & $6.1(17)$ & $1.6(1)$ & $5.3(3)$ & 4.7 (14) & $7.1(19)$ & $1.6(1)$ & $8.3(4)$ \\
\hline Ischemic & $0.9(3)$ & $2.7(8)$ & $0.0(0)$ & $5.3(3)$ & $2.9(9)$ & $5.4(15)$ & $1.6(1)$ & $5.3(3)$ & $4.4(13)$ & $5.8(16)$ & $1.6(1)$ & $5.3(3)$ \\
\hline Hemorrhagic & $0.0(0)$ & $0.3(1)$ & $0.0(0)$ & $0.0(0)$ & $0.0(0)$ & $0.7(2)$ & $0.0(0)$ & $0.0(0)$ & $0.0(0)$ & $1.3(3)$ & $0.0(0)$ & $3.1(1)$ \\
\hline Undetermined & $0.3(1)$ & $0.0(0)$ & $0.0(0)$ & $0.0(0)$ & $0.3(1)$ & $0.0(0)$ & $0.0(0)$ & $0.0(0)$ & $0.3(1)$ & $0.0(0)$ & $0.0(0)$ & $0.0(0)$ \\
\hline TIA & $0.9(3)$ & $0.3(1)$ & $0.0(0)$ & $0.0(0)$ & $2.0(6)$ & $1.9(5)$ & $0.0(0)$ & $0.0(0)$ & $3.1(9)$ & $1.9(5)$ & $0.0(0)$ & $0.0(0)$ \\
\hline $\mathrm{ICH}$ & $0.0(0)$ & $0.0(0)$ & $0.0(0)$ & $0.0(0)$ & $1.0(3)$ & $0.8(2)$ & $0.0(0)$ & $0.0(0)$ & $1.4(4)$ & $0.8(2)$ & $0.0(0)$ & $0.0(0)$ \\
\hline Encephalopathy & $7.5(24) \dagger$ & $16.0(48) \dagger$ & $19.7(13)$ & $22.9(13)$ & $11.5(36) \dagger$ & $18.6(55) \dagger$ & $21.3(14)$ & $25.0(14)$ & $12.3(38) \dagger$ & $19.4(57) \dagger$ & $21.3(14)$ & $27.5(15)$ \\
\hline
\end{tabular}

Data are presented as Kaplan-Meier estimates (no. of patients). TAVR, Transcatheter aortic valve replacement; SAVR, surgical aortic valve replacement; TIA, transient ischemic attack; $I C H$, intracranial hemorrhage. ${ }^{*} P<.05$. $\dagger P \leq .01$. neuroimaging studies. 
TABLE 4. Discharge medications for the TAVR and SAVR patients

\begin{tabular}{|c|c|c|c|}
\hline Category & TAVR $(\mathbf{n}=391), \%(\mathbf{n})$ & $\operatorname{SAVR}(\mathbf{n}=359), \%(\mathbf{n})$ & $P$ value \\
\hline Patients discharged on aspirin & $94.1(368)$ & $93.3(335)$ & .6504 \\
\hline Patients discharged on antiplatelet & $90.5(354)$ & $35.9(129)$ & $<.0001$ \\
\hline Patients discharged on anticoagulant & $59.6(233)$ & 68.8 (247) & .0087 \\
\hline Patients discharged on both aspirin and antiplatelet & $87.5(342)$ & $34.8(125)$ & $<.0001$ \\
\hline Patients discharged on both aspirin and anticoagulant & $58.1(227)$ & $65.5(235)$ & .0373 \\
\hline Patients discharged on both antiplatelet and anticoagulant & $53.7(210)$ & $24.0(86)$ & $<.0001$ \\
\hline Patients discharged on aspirin and antiplatelet and anticoagulant & $52.2(204)$ & $22.8(82)$ & $<.0001$ \\
\hline Patients discharged on aspirin or antiplatelet & $97.2(380)$ & $94.4(339)$ & .0581 \\
\hline Patients discharged on aspirin or anticoagulant & $95.7(374)$ & 96.7 (347) & .4757 \\
\hline Patients discharged on antiplatelet or anticoagulant & $96.4(377)$ & $80.8(290)$ & $<.0001$ \\
\hline Patients discharged on aspirin or antiplatelet or anticoagulant & $97.2(380)$ & $96.7(347)$ & .6745 \\
\hline
\end{tabular}

$T A V R$, Transcatheter aortic valve replacement; SAVR, surgical aortic valve replacement.

vs $2.4 \% ; P=.07){ }^{23}$ These pivotal preliminary findings launched international concerns about whether TAVR imparted a higher risk of stroke than SAVR, presumably due to the unprotected intravascular manipulation of wires and devices around the arch and through a calcified aortic valve.

These initial concerns were tempered somewhat by subsequent European Registry results and meta-analyses that demonstrated stroke rates ranging from $1 \%$ to $5 \% .^{24-27}$ The results of the CoreValve Trial further offset those of the PARTNER Trial, demonstrating equivalent stroke rates for TAVR and SAVR $(4.9 \%$ vs $6.2 \% ; P=.46)$ at 30 days. ${ }^{11}$ These results provoked criticism that the stroke rate reported for the SAVR group in the CoreValve Trial was unexpectedly high, and that this apparently higher-than-expected (compared with PARTNER data) SAVR-associated stroke rate explained the noninferior statistical findings. Of note, a recent single-institution prospective observational study of patients undergoing SAVR revealed that the neurologist-adjudicated and MRI-confirmed hospital stroke rate was more than double the stroke rate reported in the STS database (data extracted retrospectively by chart review to abstract "permanent stroke") for the same patient cohort. ${ }^{2}$ Neurologic complications in the PARTNER Trial were ascertained retrospectively by a Clinical Events Committee chart review. In contrast, in the CoreValve Trial, neurologic outcomes were ascertained prospectively with baseline neurologist-adjudicated testing for all patients, and thus there is greater confidence that all neurologic events were appropriately captured and reported. It is this discrepancy in methodology that likely explains the difference in absolute stroke rates reported by these 2 large randomized controlled trials.

In the CoreValve Trial, the combined neurologic event rates (any stroke or TIA) at 30 days, 1 year, and 2 years did not differ significantly between the TAVR and SAVR groups; however, the rate of stroke at 2 years was higher in the SAVR group. The rate of minor stroke was also significantly higher in the SAVR group at 30 days and 1 year, and the majority of these events were ischemic in origin. The rate of nonfocal, global encephalopathy was

TABLE 5. Discharge medications for TAVR and SAVR patients who had a stroke up to 2 years postprocedure

\begin{tabular}{|c|c|c|c|}
\hline Category & TAVR $(\mathbf{n}=40), \%(n)$ & $\operatorname{SAVR}(\mathbf{n}=\mathbf{5 2}), \%(\mathbf{n})$ & $P$ value \\
\hline Patients discharged on aspirin & $87.5(35)$ & $90.4(47)$ & .6595 \\
\hline Patients discharged on antiplatelet & $82.5(33)$ & $38.5(20)$ & $<.0001$ \\
\hline Patients discharged on anticoagulant & $62.5(25)$ & $75.0(39)$ & .1965 \\
\hline Patients discharged on both aspirin and antiplatelet & $77.5(31)$ & $36.5(19)$ & $<.0001$ \\
\hline Patients discharged on both aspirin and anticoagulant & $62.5(25)$ & $71.2(37)$ & .3801 \\
\hline Patients discharged on both antiplatelet and anticoagulant & $52.5(21)$ & $25.0(13)$ & .0067 \\
\hline Patients discharged on aspirin and antiplatelet and anticoagulant & $52.5(21)$ & $23.1(12)$ & .0035 \\
\hline Patients discharged on aspirin or antiplatelet & $92.5(37)$ & $92.3(48)$ & $>.9999$ \\
\hline Patients discharged on aspirin or anticoagulant & $87.5(35)$ & $94.2(49)$ & .2877 \\
\hline Patients discharged on antiplatelet or anticoagulant & $92.5(37)$ & $88.5(46)$ & .7266 \\
\hline Patients discharged on aspirin or antiplatelet or anticoagulant & $92.5(37)$ & $94.2(49)$ & $>.9999$ \\
\hline
\end{tabular}

$T A V R$, Transcatheter aortic valve replacement; $S A V R$, surgical aortic valve replacement. 
TABLE 6. Medication at discharge for TAVR and SAVR patients who had a stroke or not within 3 months postprocedure

\begin{tabular}{|c|c|c|c|c|c|c|}
\hline \multirow[b]{2}{*}{ Category } & \multicolumn{3}{|c|}{ TAVR } & \multicolumn{3}{|c|}{ SAVR } \\
\hline & $\begin{array}{c}\text { Stroke } \\
(\mathbf{n}=\mathbf{2 1})\end{array}$ & $\begin{array}{l}\text { No stroke } \\
(\mathrm{n}=354)\end{array}$ & $P$ value & $\begin{array}{c}\text { Stroke } \\
(\mathbf{n}=27)\end{array}$ & $\begin{array}{l}\text { No stroke } \\
(\mathbf{n}=302)\end{array}$ & $P$ value \\
\hline DAPT at discharge, $\%(\mathrm{n} / \mathrm{N})$ & $66.7(14 / 21)$ & $90.4(320 / 354)$ & 0007 & $40.7(11 / 27)$ & $36.4(110 / 302)$ & .6558 \\
\hline Anticoagulation at discharge, $\%(\mathrm{n} / \mathrm{N})$ & $57.1(12 / 21)$ & $60.2(213 / 354)$ & .7833 & $77.8(21 / 27)$ & $70.2(212 / 302)$ & .4065 \\
\hline
\end{tabular}

$T A V R$, Transcatheter aortic valve replacement; $S A V R$, surgical aortic valve replacement; $D A P T$, dual antiplatelet therapy.

significantly higher in the SAVR group at all time points out to 2 years. Stroke rates were highest (by more than 3 -fold) in the patients who were judged to have inadequate iliofemoral access for TAVR on preoperative evaluation and were then randomized to the SAVR group compared with those randomized to non-iliofemoral TAVR. This is consistent with previous publications reporting worse outcomes in patients with significant large-vessel lower extremity peripheral artery disease compared with the general population. ${ }^{28}$

The neurologic substudy findings are consistent with those of the whole CoreValve High-Risk Trial results showing a trend toward higher NIHSS scores and a greater drop in MMSE scores at discharge in patients undergoing SAVR compared with those undergoing TAVR. The extent and frequency of neurologic deficits as otherwise measured by visual field, gait abnormality, left or right hand motor function, writing evaluation, or drawing evaluation were similar in the TAVR and SAVR groups. The small study group size may have resulted in a lack of statistical significance, considering that both the gait assessment and the writing evaluation suggested a trend toward worse outcomes with SAVR. Overall, these detailed neurologic evaluations of the substudy uncovered more changes in indices of higher cognitive function than neurologic events adjudicated simply by the VARC definitions. How these changes impact quality of life are not yet clear, but the results of the substudy suggest that physician-reported

TABLE 7. Medications for the TAVR and SAVR patients who experienced stroke within 3 months and 1 year postprocedure

\begin{tabular}{|c|c|c|c|}
\hline Category & TAVR, $\%(\mathbf{n} / \mathbf{N})$ & SAVR, \% $(\mathbf{n} / \mathbf{N})$ & $\begin{array}{c}P \\
\text { value }\end{array}$ \\
\hline \multicolumn{4}{|c|}{$\begin{array}{l}\text { TAVR }(\mathrm{n}=21) \text { and SAVR }(\mathrm{n}=27) \text { patients who experienced stroke } \\
\text { within } 3 \text { months postprocedure }\end{array}$} \\
\hline DAPT at discharge & $66.7(14 / 21)$ & $40.7(11 / 27)$ & .0745 \\
\hline $\begin{array}{l}\text { Anticoagulation } \\
\text { at discharge }\end{array}$ & $57.1(12 / 21)$ & $77.8(21 / 27)$ & .1260 \\
\hline \multicolumn{4}{|c|}{$\begin{array}{l}\text { TAVR }(\mathrm{n}=33) \text { and SAVR }(\mathrm{n}=42) \text { patients who experienced stroke } \\
\text { within } 1 \text { year postprocedure }\end{array}$} \\
\hline DAPT at discharge & $75.8(25 / 33)$ & $35.7(15 / 42)$ & .0006 \\
\hline $\begin{array}{l}\text { Anticoagulation } \\
\text { at discharge }\end{array}$ & $63.6(21 / 33)$ & $76.2(32 / 42)$ & .2359 \\
\hline
\end{tabular}

$T A V R$, Transcatheter aortic valve replacement; $S A V R$, surgical aortic valve replacement; $D A P T$, dual antiplatelet therapy. neurologic outcome assessments underestimate true neurologic event rates.

Univariate and multivariate analysis revealed multiple predictors of neurologic events (Table 2). The presence of peripheral vascular disease and a history of previous fall predicted a higher incidence of stroke at 30 days among the TAVR patients. A Charlson Comorbidity Index score of $\geq 5$ and severe aortic calcification predicted a higher incidence of stroke at 1 year. One surprising finding was that new-onset atrial fibrillation was not an independent predictor for stroke, in disagreement with a previous retrospective report. $^{29}$

According to the CoreValve Trial design, there is no requirement to discharge SAVR patients on aspirin or an antiplatelet agent (eg, clopidogrel), and there is only a strong recommendation to discharge TAVR patients on DAPT unless medically contraindicated. Consequently, and as expected, a significantly higher percentage of TAVR patients $(88 \%)$ than SAVR patients $(35 \%)$ were discharged on an antiplatelet agent in addition to aspirin. The lack of use of DAPT after TAVR was associated with a greater risk of stroke; however, this same association did not hold for the SAVR patients, suggesting that DAPT may have a more defined role for TAVR but not necessarily for SAVR. It must be emphasized that despite differing medication regimens, this study provides some evidence that DAPT may lead to a reduced stroke rate, particularly with TAVR.

A limitation of the neurologic substudy is that only $27 \%$ of the entire trial enrollment participated in it, reducing the statistical power of the dataset. With respect to the whole CoreValve Trial, medication use extending beyond the first several months postdischarge was not collected, and so the exact duration of DAPT in each arm is not known. Moreover, the medication data were based on case report forms, and thus were dependent on site-reporting accuracy. Thus, the points in the discussion pertain to a planned 3- to 6-month duration of DAPT in those patients who received TAVR.

\section{CONCLUSIONS}

The neurologic outcomes analyses of the CoreValve Trial and neurologic substudy show that the neurologistadjudicated stroke rate is at least equivalent following either 
TABLE 8. Baseline clinical characteristics, comorbidity, disability, and frailty assessments at baseline for patients in the high-risk neurologic substudy

\begin{tabular}{|c|c|c|c|}
\hline Characteristic & $\begin{array}{c}\text { TAVR } \\
(\mathbf{n}=\mathbf{1 1 1})\end{array}$ & $\begin{array}{c}\text { SAVR } \\
(\mathbf{n}=\mathbf{8 8})\end{array}$ & $\begin{array}{c}P \\
\text { value }\end{array}$ \\
\hline Age, $y$, mean \pm SD & $82.3 \pm 7.4$ & $83.7 \pm 7.3$ & .20 \\
\hline Male sex & $55.0(61 / 111)$ & $59.1(52 / 88)$ & .56 \\
\hline NYHA class III/IV & $89.2(99 / 111)$ & $87.5(77 / 88)$ & .71 \\
\hline $\begin{array}{l}\text { STS score, } \% \\
\text { mean } \pm \text { SD }\end{array}$ & $7.0 \pm 3.0$ & $7.4 \pm 3.7$ & .31 \\
\hline $\begin{array}{l}\text { Logistic EuroSCORE, } \\
\%, \text { mean } \pm \text { SD }\end{array}$ & $17.2 \pm 13.8$ & $18.6 \pm 14.1$ & .49 \\
\hline Diabetes mellitus & $35.1(39 / 111)$ & $36.4(32 / 88)$ & .86 \\
\hline Controlled by insulin & $9.0(10 / 111)$ & $11.4(10 / 88)$ & .58 \\
\hline $\begin{array}{l}\text { Peripheral vascular } \\
\text { disease }\end{array}$ & $43.5(47 / 108)$ & $48.3(42 / 87)$ & .51 \\
\hline $\begin{array}{l}\text { Atrial fibrillation/ } \\
\text { flutter }\end{array}$ & $40.5(45 / 111)$ & $42.0(37 / 88)$ & .83 \\
\hline Total NIHSS score & & & .55 \\
\hline 0 & $84.2(85 / 101)$ & $80.8(63 / 78)$ & \\
\hline $1-5$ & $15.8(16 / 101)$ & $19.2(15 / 78)$ & \\
\hline $6-10$ & 0.0 & 0.0 & \\
\hline$>10$ & 0.0 & 0.0 & \\
\hline Previous stroke & $17.1(19 / 111)$ & $14.8(13 / 88)$ & .65 \\
\hline $\begin{array}{l}\text { NIHSS score (for the } \\
\text { previous stroke) }\end{array}$ & & & .64 \\
\hline 0 & $72.2(13 / 18)$ & $63.6(7 / 11)$ & \\
\hline $1-5$ & $27.8(5 / 18)$ & $36.4(4 / 11)$ & \\
\hline $6-10$ & 0.0 & 0.0 & \\
\hline$>10$ & 0.0 & 0.0 & \\
\hline $\begin{array}{l}\text { mRS score (for the } \\
\text { previous stroke) }\end{array}$ & & & .25 \\
\hline 0 & $50.0(9 / 18)$ & $66.7(8 / 12)$ & \\
\hline 1 & $22.2(4 / 18)$ & $25.0(3 / 12)$ & \\
\hline 2 & $16.7(3 / 18)$ & $8.3(1 / 12)$ & \\
\hline 3 & $5.6(1 / 18)$ & 0.0 & \\
\hline 4 & $5.6(1 / 18)$ & 0.0 & \\
\hline 5 & 0.0 & 0.0 & \\
\hline Previous TIA & $18.0(20 / 111)$ & $15.9(14 / 88)$ & .69 \\
\hline Home oxygen & $9.1(10 / 110)$ & $9.1(8 / 88)$ & $>.99$ \\
\hline $\begin{array}{l}\text { Charlson Comorbidity } \\
\text { score } \geq 5\end{array}$ & $51.4(57 / 111)$ & $62.5(55 / 88)$ & .11 \\
\hline Anemia & $14.2(15 / 106)$ & $11.1(9 / 81)$ & .54 \\
\hline Albumin $<3.3 \mathrm{~g} / \mathrm{dL}$ & $10.1(11 / 109)$ & $13.3(11 / 83)$ & .50 \\
\hline Unplanned weight loss & $7.2(8 / 111)$ & $8.0(7 / 88)$ & .84 \\
\hline $\begin{array}{l}\text { 5-meter gait } \\
\text { speed }>6 \mathrm{~s}\end{array}$ & $78.4(80 / 102)$ & $79.3(65 / 82)$ & .89 \\
\hline $\begin{array}{l}\text { Grip strength below } \\
\text { threshold }\end{array}$ & $63.6(70 / 110)$ & $66.7(58 / 87)$ & .66 \\
\hline Falls in past $6 \mathrm{mo}$ & $20.7(23 / 111)$ & $20.5(18 / 88)$ & .96 \\
\hline Wheelchair bound & $1.8(2 / 111)$ & $3.4(3 / 88)$ & .66 \\
\hline $\begin{array}{l}\text { Does not live } \\
\text { independently }\end{array}$ & $3.6(4 / 111)$ & $8.0(7 / 88)$ & .22 \\
\hline \multicolumn{4}{|c|}{ Katz Index of activities of daily living } \\
\hline$\geq 2$ deficits & 0.0 & $2.3(2 / 88)$ & .19 \\
\hline MMSE score & $26.7 \pm 2.6(110)$ & $26.4 \pm 2.8(88)$ & .55 \\
\hline Normal $(\geq 25)$ & $78.2(86 / 110)$ & $75.0(66 / 88)$ & .62 \\
\hline
\end{tabular}

TABLE 8. Continued

\begin{tabular}{lccc}
\hline Characteristic & TAVR & SAVR & $\boldsymbol{P}$ \\
$(\mathbf{n}=\mathbf{1 1 1})$ & $(\mathbf{n = 8 8})$ & value \\
\hline Mild $(21-24)$ & $18.2(20 / 110)$ & $21.6(19 / 88)$ & \\
Moderate $(10-20)$ & $3.6(4 / 110)$ & $3.4(3 / 88)$ & \\
Severe $(<10)$ & 0.0 & 0.0 & \\
\hline
\end{tabular}

TAVR, Transcatheter aortic valve replacement; $S A V R$, surgical aortic valve replacement; $S D$, standard deviation; $N Y H A$, New York Heart Association; STS, Society of Thoracic Surgeons; EuroSCORE, European System for Cardiac Operative Risk Evaluation; NIHSS, National Institutes of Health Stroke Scale; $m R S$, modified Rankin Scale; TIA, transient ischemic attack; MMSE, Mini-Mental Status Examination.

TAVR or SAVR, and that the extent of neurologic impairment caused by the strokes is also similar. These findings hold out to 2 years after aortic valve replacement, and are in contrast to previous reports of a higher stroke rate associated with TAVR compared with SAVR. ${ }^{23,30-32}$ The mortality rate in stroke is very high by 2 years, and more than double after TAVR compared with SAVR (Figure 4, A); thus, clearly stroke remains an important problem with any aortic valve intervention. Focus should now shift toward improving methods that will further mitigate stroke risk, including the use of less traumatic, more easily maneuverable devices or of embolic debris filters that prevent or limit embolic phenomena. In addition, results of ongoing clinical trials aimed at identifying optimal antiplatelet/anticoagulation regimens after TAVR or for patients with atrial dysrhythmias or other indications for anticoagulation should be helpful. In light of recognized deficiencies in stroke prevention and detection, more rigorous and widespread adoption of neurologistadjudicated stroke surveillance is warranted for all cardiovascular procedures.

\section{Webcast}

You can watch a Webcast of this AATS meeting presentation by going to: http://www.jtcvsonline.org/article/ S0022-5223(16)00433-5/addons.

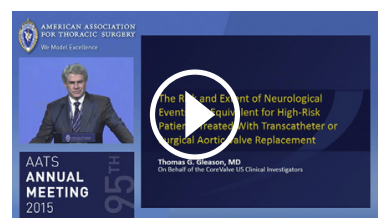

\section{Conflict of Interest Statement}

T.G.G., J.T.S., G.M.C., and N.S.K. have received institutional research grants from Medtronic but no personal income. D.H.A. has received institutional grants and institutional royalties for patents with Medtronic, and institutional royalties for patents with Edwards Lifesciences, and serves on a medical advisory board for 
TABLE 9. Changes from baseline in neurologic assessment measures for patients in the neurologic substudy

\begin{tabular}{|c|c|c|c|}
\hline Characteristic & TAVR & SAVR & $P$ value \\
\hline \multicolumn{4}{|l|}{ NIHSS } \\
\hline \multicolumn{4}{|l|}{ Discharge } \\
\hline Increased by $\geq 2, \%(\mathrm{n} / \mathrm{N})$ & $3.5(3 / 85)$ & $12.7(8 / 63)$ & .05 \\
\hline Without neurologic event, $\mathrm{n} / \mathrm{N}$ & $0 / 3$ & $5 / 8$ & \\
\hline With neurologic event, $\mathrm{n} / \mathrm{N}$ & $3 / 3$ & $3 / 8$ & \\
\hline \multicolumn{4}{|l|}{$1 \mathrm{y}$} \\
\hline Increased by $\geq 2, \%(\mathrm{n} / \mathrm{N})$ & $1.5(1 / 65)$ & $4.9(2 / 41)$ & .56 \\
\hline Without neurologic event, $\mathrm{n} / \mathrm{N}$ & $0 / 1$ & $0 / 2$ & \\
\hline With neurologic event, $\mathrm{n} / \mathrm{N}$ & $1 / 1$ & $2 / 2$ & \\
\hline \multicolumn{4}{|l|}{ MMSE } \\
\hline \multicolumn{4}{|l|}{ Discharge } \\
\hline Decreased by $>4, \%(\mathrm{n} / \mathrm{N})$ & $2.5(2 / 79)$ & $10.9(6 / 55)$ & .06 \\
\hline Without neurologic event, $\mathrm{n} / \mathrm{N}$ & $0 / 2$ & $4 / 6$ & \\
\hline With neurologic event, $\mathrm{n} / \mathrm{N}$ & $2 / 2$ & $2 / 6$ & \\
\hline \multicolumn{4}{|l|}{$1 \mathrm{y}$} \\
\hline Decreased by $>4, \%(\mathrm{n} / \mathrm{N})$ & $8.1(5 / 62)$ & $2.5(1 / 40)$ & .40 \\
\hline Without neurologic event, $\mathrm{n} / \mathrm{N}$ & $4 / 5$ & $0 / 1$ & \\
\hline With neurologic event, $\mathrm{n} / \mathrm{N}$ & $1 / 5$ & $1 / 1$ & \\
\hline \multicolumn{4}{|l|}{ New gait abnormality } \\
\hline Discharge, $\%(\mathrm{n} / \mathrm{N})$ & $7.8(6 / 77)$ & $15.5(9 / 58)$ & .16 \\
\hline Without neurologic event, $\mathrm{n} / \mathrm{N}$ & $5 / 6$ & $7 / 9$ & \\
\hline With neurologic event, $\mathrm{n} / \mathrm{N}$ & $1 / 6$ & $2 / 9$ & \\
\hline $1 \mathrm{y}, \%(\mathrm{n} / \mathrm{N})$ & $6.8(4 / 59)$ & $7.7(3 / 39)$ & $>.99$ \\
\hline Without neurologic event, $\mathrm{n} / \mathrm{N}$ & $3 / 4$ & $3 / 3$ & \\
\hline With neurologic event, $\mathrm{n} / \mathrm{N}$ & $1 / 4$ & 0 & \\
\hline \multicolumn{4}{|l|}{ Weakness in left hand motor function } \\
\hline Discharge, $\%(\mathrm{n} / \mathrm{N})$ & $7.2(5 / 69)$ & $6.5(3 / 46)$ & $>.99$ \\
\hline Without neurologic event, $\mathrm{n} / \mathrm{N}$ & $5 / 5$ & $3 / 3$ & \\
\hline With neurologic event, $\mathrm{n} / \mathrm{N}$ & 0 & 0 & \\
\hline $1 \mathrm{y}, \%(\mathrm{n} / \mathrm{N})$ & $0.0(0 / 56)$ & $5.7(2 / 35)$ & .14 \\
\hline Without neurologic event, $\mathrm{n} / \mathrm{N}$ & 0 & $1 / 2$ & \\
\hline With neurologic event, $\mathrm{n} / \mathrm{N}$ & 0 & $1 / 2$ & \\
\hline \multicolumn{4}{|c|}{ Weakness in right hand motor function } \\
\hline Discharge, $\%(\mathrm{n} / \mathrm{N})$ & $7.2(5 / 69)$ & $10.4(5 / 48)$ & .74 \\
\hline Without neurologic event, $\mathrm{n} / \mathrm{N}$ & $3 / 5$ & $5 / 5$ & \\
\hline With neurologic event, $\mathrm{n} / \mathrm{N}$ & $2 / 5$ & $0 / 5$ & \\
\hline $1 \mathrm{y}, \%(\mathrm{n} / \mathrm{N})$ & $0.0(0 / 55)$ & $5.4(2 / 37)$ & .16 \\
\hline Without neurologic event, $\mathrm{n} / \mathrm{N}$ & 0 & $0 / 2$ & \\
\hline With neurologic event, $\mathrm{n} / \mathrm{N}$ & 0 & $2 / 2$ & \\
\hline \multicolumn{4}{|l|}{ Failed writing evaluation } \\
\hline Discharge, $\%(\mathrm{n} / \mathrm{N})$ & $5.1(4 / 79)$ & $8.5(5 / 59)$ & .50 \\
\hline Without neurologic event, $\mathrm{n} / \mathrm{N}$ & $3 / 4$ & $4 / 5$ & \\
\hline With neurologic event, $\mathrm{n} / \mathrm{N}$ & $1 / 4$ & $1 / 5$ & \\
\hline $1 \mathrm{y}$ & $1.6(1 / 61)$ & $10.0(4 / 40)$ & .08 \\
\hline Without neurologic event, $\mathrm{n} / \mathrm{N}$ & $1 / 1$ & $3 / 4$ & \\
\hline With neurologic event, $\mathrm{n} / \mathrm{N}$ & 0 & $1 / 4$ & \\
\hline \multicolumn{4}{|l|}{ Failed drawing evaluation } \\
\hline Discharge, $\%(\mathrm{n} / \mathrm{N})$ & $23.5(12 / 51)$ & $25.6(10 / 39)$ & .82 \\
\hline Without neurologic event, $\mathrm{n} / \mathrm{N}$ & $10 / 12$ & $8 / 10$ & \\
\hline With neurologic event, $\mathrm{n} / \mathrm{N}$ & $2 / 12$ & $2 / 10$ & \\
\hline $1 \mathrm{y}, \%(\mathrm{n} / \mathrm{N})$ & $10.9(5 / 46)$ & $11.1(3 / 27)$ & $>.99$ \\
\hline Without neurologic event, $\mathrm{n} / \mathrm{N}$ & $5 / 5$ & $1 / 3$ & \\
\hline With neurologic event, $\mathrm{n} / \mathrm{N}$ & $0 / 5$ & $2 / 3$ & \\
\hline
\end{tabular}

$T A V R$, Transcatheter aortic valve replacement; $S A V R$, surgical aortic valve replacement; NIHSS, National Institutes of Health Stoke Scale; MMSE, Mini-Mental Status Examination.
Boston Scientific. M.J.R. has received institutional research grants from and serves on a medical advisory board for Medtronic. J.V.C. receives grant support and fees from Medtronic, Boston Scientific, and Sorin and has received institutional grants from Medtronic, but no personal income. G.C.H. has no disclosures. S.C. is an employee and shareholder of Medtronic. J.J.P. has received institutional research grants from Medtronic, Boston Scientific, and Direct Flow Medical. The other author has nothing to disclose with regard to commercial support.

We thank Gloria Toledo and Joleen Perkins for study management and Jane Moore, Holly Vitense, and Colleen Gilbert for statistical and editorial support. Medtronic, Inc sponsored this trial and participated in the design of the study in concert with the study Steering Committee.

\section{References}

1. Salazar JD, Wityk RJ, Grega MA, Borowicz LM, Doty JR, Petrofski JA, et al. Stroke after cardiac surgery: short- and long-term outcomes. Ann Thorac Surg. 2001;72:1195-201.

2. Messé SR, Acker MA, Kasner SE, Fanning M, Giovannetti T, Ratcliffe SJ, et al. Stroke after aortic valve surgery: results from a prospective cohort. Circulation. 2014;129:2253-61.

3. Miller DC, Blackstone EH, Mack MJ, Svensson LG, Kodali SK, Kapadia S, et al. Transcatheter (TAVR) versus surgical (AVR) aortic valve replacement: occurrence, hazard, risk factors, and consequences of neurologic events in the PARTNER trial. J Thorac Cardiovasc Surg. 2012; 143:832-43.e13.

4. Leon MB, Piazza N, Nikolsky E, Blackstone EH, Cutlip DE, Kappetein AP, et al. Standardized endpoint definitions for transcatheter aortic valve implantation clinical trials: a consensus report from the Valve Academic Research Consortium. J Am Coll Cardiol. 2011;57:253-69.

5. Arnold M, Schulz-Heise S, Achenbach S, Ott S, Dörfler A, Ropers D, et al. Embolic cerebral insults after transapical aortic valve implantation detected by magnetic resonance imaging. JACC Cardiovasc Interv. 2010; 3:1126-32.

6. Ghanem A, Müller A, Nähle CP, Kocurek J, Werner N, Hammerstingl C, et al. Risk and fate of cerebral embolism after transfemoral aortic valve implantation: a prospective pilot study with diffusion-weighted magnetic resonance imaging. J Am Coll Cardiol. 2010;55:1427-32.

7. Kahlert P, Al-Rashid F, Döttger P, Mori K, Plicht B, Wendt D, et al. Cerebral embolization during transcatheter aortic valve implantation: a transcranial Doppler study. Circulation. 2012;126:1245-55.

8. Kahlert P, Knipp SC, Schlamann M, Thielmann M, Al-Rashid F, Weber M, et al. Silent and apparent cerebral ischemia after percutaneous transfemoral aortic valve implantation: a diffusion-weighted magnetic resonance imaging study. Circulation. 2010;121:870-8.

9. Fairbairn TA, Mather AN, Bijsterveld P, Worthy G, Currie S, Goddard AJ, et al. Diffusion-weighted MRI determined cerebral embolic infarction following transcatheter aortic valve implantation: assessment of predictive risk factors and the relationship to subsequent health status. Heart. 2012; 98:18-23.

10. Knipp SC, Matatko N, Schlamann M, Wilhelm H, Thielmann M, Forsting M, et al. Small ischemic brain lesions after cardiac valve replacement detected by diffusion-weighted magnetic resonance imaging: relation to neurocognitive function. Eur J Cardiothorac Surg. 2005;28:88-96.

11. Adams DH, Popma JJ, Reardon MJ, Yakubov SJ, Coselli JS, Deeb GM, et al. Transcatheter aortic-valve replacement with a self-expanding prosthesis. N Engl J Med. 2014;370:1790-8.

12. Leon MB, Piazza N, Nikolsky E, Blackstone EH, Cutlip DE, Kappetein AP, et al. Standardized endpoint definitions for transcatheter aortic valve implantation clinical trials: a consensus report from the Valve Academic Research Consortium. Eur Heart J. 2011;32:205-17. 
13. Sulter G, Steen C, De Keyser J. Use of the Barthel index and modified Rankin scale in acute stroke trials. Stroke. 1999;30:1538-41.

14. Folstein MF, Folstein SE, McHugh PR. "Mini-mental state": a practical method for grading the cognitive state of patients for the clinician. J Psychiatr Res. 1975; 12:189-98.

15. Crum RM, Anthony JC, Bassett SS, Folstein MF. Population-based norms for the Mini-Mental State Examination by age and educational level. JAMA. 1993;269: 2386-91.

16. McKhann GM, Grega MA, Borowicz LM Jr, Bechamps M, Selnes OA, Baumgartner WA, et al. Encephalopathy and stroke after coronary artery bypass grafting: incidence, consequences, and prediction. Arch Neurol. 2002;59:1422-8.

17. Adams DH, Popma JJ, Reardon MJ. Transcatheter aortic-valve replacement with a self-expanding prosthesis. N Engl J Med. 2014;371:967-8.

18. Tuijl JP, Scholte EM, de Craen AJ, van der Mast RC. Screening for cognitive impairment in older general hospital patients: comparison of the Six-Item Cognitive Impairment Test with the Mini-Mental State Examination. Int $J$ Geriatr Psychiatry. 2012;27:755-62.

19. Medical Research Council. Aids to examination of the peripheral nervous system. Available at: https://www.mrc.ac.uk/documents/pdf/aids-to-the-exami nation-of-the-peripheral-nervous-system-mrc-memorandum-no-45-supersedingwar-memorandum-no-7/.

20. Kendall FP, McCreary EK, Provance PG, Rodgers MM, Romani WA. Muscles: Testing and Function, with Posture and Pain. 4th ed. Baltimore: Williams \& Wilkins; 1993.

21. Reardon MJ, Adams DH, Kleiman NS, Yakubov SJ, Coselli JS, Deeb GM, et al. Two-year outcomes in patients undergoing surgical or self-expanding transcatheter aortic valve replacement. J Am Coll Cardiol. 2015;66:113-21.

22. Leon MB, Smith CR, Mack M, Miller DC, Moses JW, Svensson LG, et al. Transcatheter aortic-valve implantation for aortic stenosis in patients who cannot undergo surgery. N Engl J Med. 2010;363:1597-607.

23. Smith CR, Leon MB, Mack MJ, Miller DC, Moses JW, Svensson LG, et al. Transcatheter versus surgical aortic-valve replacement in high-risk patients. N Engl J Med. 2011;364:2187-98.

24. Eltchaninoff H, Prat A, Gilard M, Leguerrier A, Blanchard D, Fournial G, et al. Transcatheter aortic valve implantation: early results of the FRANCE (FRench Aortic National CoreValve and Edwards) registry. Eur Heart J. 2011;32:191-7.

25. Moat NE, Ludman P, de Belder MA, Bridgewater B, Cunningham AD, Young CP, et al. Long-term outcomes after transcatheter aortic valve implantation in high-risk patients with severe aortic stenosis: the UK TAVI (United Kingdom Transcatheter Aortic Valve Implantation) Registry. J Am Coll Cardiol. 2011;58:2130-8.

26. Zahn R, Gerckens U, Grube E, Linke A, Sievert H, Eggebrecht H, et al. Transcatheter aortic valve implantation: first results from a multi-centre real-world registry. Eur Heart J. 2011;32:198-204.

27. Eggebrecht H, Schmermund A, Voigtländer T, Kahlert P, Erbel R, Mehta RH. Risk of stroke after transcatheter aortic valve implantation (TAVI): a meta-analysis of 10,037 published patients. EuroIntervention. 2012;8: 129-38.

28. Criqui MH, Langer RD, Fronek A, Feigelson HS, Klauber MR, McCann TJ, et al. Mortality over a period of 10 years in patients with peripheral arterial disease. N Engl J Med. 1992;326:381-6.

29. Nuis RJ, Van Mieghem NM, Schultz CJ, Moelker A, van der Boon RM, van Geuns RJ, et al. Frequency and causes of stroke during or after transcatheter aortic valve implantation. Am J Cardiol. 2012;109:1637-43.

30. Daneault B, Kirtane AJ, Kodali SK, Williams MR, Genereux P, Reiss GR, et al. Stroke associated with surgical and transcatheter treatment of aortic stenosis: a comprehensive review. J Am Coll Cardiol. 2011;58:2143-50.

31. Stortecky S, Wenaweser P, Windecker S. Transcatheter aortic valve implantation and cerebrovascular accidents. EuroIntervention. 2012;8(Suppl Q):Q60-9.

32. Athappan G, Gajulapalli RD, Sengodan P, Bardwaj A, Ellis SG, Svensson L, et al. Influence of transcatheter aortic valve replacement strategy and valve design on stroke after transcatheter aortic valve replacement: a metaanalysis and systematic review of literature. J Am Coll Cardiol. 2014;63: 2101-10.

Key Words: aortic stenosis, surgical aortic valve replacement, transcatheter aortic valve replacement, neurologic outcomes, stroke

\section{Discussion}

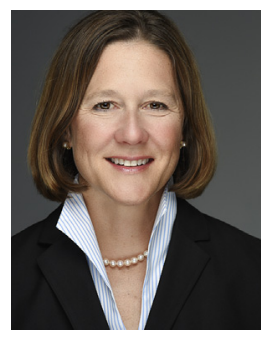

Dr J. Lawton (St Louis, Mo). Dr Gleason, excellent presentation, thank you for giving me your manuscript. I enjoyed reading it, and I enjoyed your presentation.

In this subgroup analysis of the CoreValve Pivotal Trial in 199 patients, first I have a couple of questions about how you did the trial. Were the patients randomized first, or was the iliofemoral access suitability determined first?

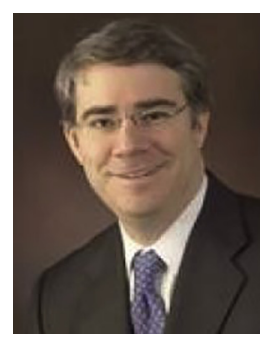

Dr Gleason (Pittsburgh, Pa). Thank you Dr Lawton. Access suitability was determined prior to randomization. As a point of clarity, if you're alluding to how the neuro substudy patients were chosen, this was dependent on whether a study site was participating in the neuro substudy. It was not a requirement for a site to be in the neuro substudy to be in the overall trial, but it was mandatory for involvement and entry into the substudy to have a neurologist on site fully engaged in the trial. So for institutions that had a bona fide neurologist on the study, those were the centers that contributed to the neuro substudy.

Dr Lawton. And having said that, how do you define major stroke versus minor stroke? And encephalopathy, I take it, was a totally separate group?

Dr Gleason. That is correct. Encephalopathy was tabulated as a separate outcome; however, for the slides that you saw as "all stroke," encephalopathy was included. In other words, "all stroke" denotes major stroke, minor stroke, and encephalopathy. As far as definitions, we used VARC-1 definitions for minor and major for the Pivotal Trial and neuro substudies. VARC-1 defines minor as a Rankin score less than 2 and major greater than 2 .

Dr Lawton. And for those of us who don't put in the CoreValve, could you perhaps contrast it to the previous studies comparing surgical AVR and transcatheter AVR in terms of differences in implantation in terms of blowing a balloon up, and also delivery size with respect to the risk of stroke and how you think this valve may be different?

Dr Gleason. That's a good question, and I can only give you my personal opinion on this point. We are an institution that uses several of the devices including the Sapien, and I would at this point argue that there is no difference in stroke risk; I think they are equivalent.

Not all, but most, of the patients in the High-Risk Pivotal Trial did get balloon valvuloplasty at the time of implant either prior to or after CoreValve deployment. Now, most groups, including our own do not do a predeployment valvuloplasty with the CoreValve device, and this may be one argument in favor of CoreValve for certain patients. 
The short answer is that I suspect the stroke risks are equivalent.

Dr Lawton. And I appreciated the scatterplots of the strokes that occurred within 30 days versus over the 2-year period of your follow-up, and that raises the question of should we really be attributing strokes after 30 days to be related to the procedure? You demonstrated a very high risk of death in those patients that had stroke, and that could be a late stroke too. So should we include all those late strokes and attribute them to perhaps the valve, the implantation technique, or patient risk factors?

Dr Gleason. Frankly, I think all are relevant, but I also think it's important to continue to study the issue. I will point out that one of the interesting aspects about stroke adjudication and stroke reporting-it's striking, actually-is that there is likely widespread underreporting. The University of Pennsylvania group recently published a fairly comprehensive study of their own site that was NIH-sponsored and had a population of approximately 200 patients, who they followed prospectively with preoperative assessment for stroke. Every patient was adjudicated post-AVR by neurologists and by neuroimaging with MRIs. They showed that the STS-reported stroke rate in that group by that same site in the same patients using the retrospective methods of chart review from which the STS database is based was half the actual neurologist-adjudicated stroke rate.

So, in other words, when we use the STS database and claim that the stroke risk based on this dataset for an AVR is, say, $1 \%$ to $2 \%$, this recent study clearly demonstrated that that's probably inaccurate, and this is largely due to this issue of nonneurologist and retrospectively adjudicated stroke.
Dr Lawton. And lastly, in those patients who are not suitable for the iliofemoral approach prior to randomization, those are clearly very high risk based on your data. Do you have any advice or tips for dealing with those patients, or are they just high-risk peripheral vascular disease patients for any cardiac surgery?

Dr Gleason. Well, it was an interesting finding that we did not expect. As you recall, the surgical patients, those treated surgically who had prohibitive iliofemoral disease, had a higher risk of stroke. Reconciling why this was the case is not entirely clear to me, because most of those patients were accessed either by direct aortic access or by subclavian, either of which could in theory portend a higher risk of stroke. So I don't really know why this occurred, but you may be correct, that bad iliofemoral disease is a marker for bad vascular disease throughout, and it is this fact that raised the stroke rate in the surgical AVR-treated group.

As far as advice, I think this is very much a changing game. With this study, I think we can move beyond tabulating what the risk is and move into an era focused on how we can prevent it. There are now deflection devices and filters that will likely be implemented in short order.

That's another question that we didn't quite address, but the conjecture is that most of these strokes are embolic, and thus perhaps a large percentage are preventable, particularly the early ones.

Dr Lawton. And the surgical patients included miniaccess, total sternotomy, any type of surgical approach?

Dr Gleason. It was a mix, but the great majority were median sternotomy. 